\title{
Transformações da subjetividade no exercício do trabalho imaterial
}

\section{Subjectiveness transformations in the practice of the immaterial work}

\section{Sonia Regina Vargas Mansano *}

Docente do Departamento de Psicologia Social e Institucional da Universidade Estadual de Londrina, Londrina, Paraná, Brasil

\begin{abstract}
Resumo
É perceptível que as relações de trabalho sofreram diferentes transformações nas últimas décadas, alterando a maneira como cada trabalhador implica-se com suas atividades. Uma dessas mudanças pode ser notada na crescente demanda por um conjunto de novas habilidades, mais centradas no conhecimento, na inventividade e nas relações sociais. Trata-se do chamado trabalho imaterial, cujo resultado não culmina na produção de bens palpáveis nem quantificáveis, mas na elaboração e na experimentação de saberes, afetos e relações sociais. Investigar quais as novas exigências subjetivas que essas transformações trazem para a vida do trabalhador, tanto no que se refere ao seu local de trabalho quanto na vida que acontece para além dele, é o objetivo deste estudo.
\end{abstract}

Palavras-chave: Trabalho imaterial, Subjetividade, Resistência.

\begin{abstract}
It is noticed that the work relationships suffered different transformations in the last decades, changing the manner which each employee involves with his activities. One of these changes can be verified on the rising demand for a series of new abilities, more focused on the knowledge, on the innovation and its social relationships. It deals with the entitled immaterial work, whose result does not achieve the top of the production of neither specific nor quantified properties, but the elaboration and experimentation of acknowledgements, affects and social relationships. Investigate what the new subjective requirements which these transformations bring to the employee's life are, as much according to his job place as the life which happens beyond him, is the goal of this studying.
\end{abstract}

Keywords: Immaterial work, Subjectiveness, Resisting. 
O desenvolvimento recente das sociedades capitalistas, particularmente acelerado nas últimas décadas pela produção tecnológica e informacional, colocou em destaque a emergência de todo um conjunto de categorias de trabalhadores cuja produção não pode mais ser caracterizada como exclusivamente material. Resultante desse processo, a "prestação de serviços" passou a ser recorrentemente utilizada para definir este campo composto por profissionais que integram diferentes formas de produção distintas da material. Trata-se de trabalhos que envolvem outras dimensões da atividade humana, particularmente aquelas voltadas para a educação, a cultura, a geração de conhecimento, a saúde, o afeto e a sociabilidade.

A emergência de novas categorias profissionais, cujo centro não se encontra na produção material, afirma-se até os dias de hoje, fazendo surgir novos modos de subjetivação entre os trabalhadores e, acreditamos também, novas relações com o próprio trabalho. Nesta perspectiva, autores como Antonio Negri (2001), Michael Hardt (2001), Maurício Lazzarato (2001) e André Gorz (2005) buscam delinear as tendências emergentes no mundo do trabalho, denominando e caracterizando essas atividades como trabalho imaterial. Para Negri e Hardt, esse tipo de atividade "produz um bem imaterial, como serviço, produto cultural, conhecimento ou comunicação" (2001, p. 311). Podemos notar, então, que um dos objetivos desses autores, ao recorrerem à categoria de trabalho imaterial, consiste em circunscrever um conjunto de atividades que guardam certa vizinhança com aquilo que até então era denominado como prestação de serviços. No entanto, este é apenas um ponto de partida.

Efetivamente, a noção de trabalho imaterial envolve a complexidade de um humano profundamente transformado pela aquisição de conhecimento e pela interação com o meio social, também ele transformado, que tem à sua disposição equipamentos de alta tecnologia, tornados impensáveis em algumas áreas profissionais.

Esta noção também permite compreender o movimento histórico atual, no qual um contingente cada vez maior de indivíduos dedica-se a trabalhar com outros seres humanos, fazendo da relação com eles, ou seja, fazendo dos vínculos afetivos construídos nos encontros sociais, o próprio objetivo do trabalho.

Destacam-se na explicitação do trabalho imaterial proposta por Negri e Hardt (2001), três campos de atividade distintos. Primeiramente, o trabalho imaterial poderia ser pensado como produção no campo de "serviços simbólico-analíticos" (p. 312), sendo que este engloba a "resolução de problemas, a identificação de problemas, e atividades estratégicas de intermediação" (p. 312). Nesse campo, o trabalho imaterial efetua-se ao tomar em análise a complexidade presente nas 
sociedades contemporâneas, convocando o trabalhador a identificar, resolver e mesmo criar novos problemas. Trata-se de uma atividade que busca fazer a mediação entre as diferentes esferas de produção material, criando condições para uma organização descentralizada, mas que, ainda assim, mantém articulações precisas junto ao produto final. $O$ trabalho imaterial envolve, nesta primeira caracterização, as capacidades de análise e de abstração, a partir das quais os trabalhadores percorrem diferentes domínios do conhecimento, cada um deles associado a um componente do produto final.

Com isso, o trabalhador é solicitado a conhecer todo o processo de produção e a colaborar para aperfeiçoá-lo, expondo suas percepções e opiniões, ainda que elas não tenham a sofisticação de um saber técnico. Percebe-se que o conhecimento baseado na experiência ganha importância atualmente e passa a ser valorizado como um diferencial. Além disso, tanto a capacidade para tomar decisões quanto a habilidade para enfrentar situações que são inéditas e imprevisíveis demandam a articulação direta entre o fazer e o pensar, exigindo uma implicação subjetiva do trabalhador para com o processo produtivo.

Numa segunda perspectiva, o trabalho imaterial já não é mais aquele que se responsabiliza por integrar diferentes conhecimentos sobre o produto em questão. O que se pretende agora é intervir no sentido de intermediar a relação entre o produto material e o mercado consumidor. Aqui, novas funções são incorporadas no trato com o produto. Pode-se considerar, em princípio, que esta vertente ocupa-se da análise e da produção da demanda. Isso envolve uma estrutura complexa que vai desde a pesquisa sobre as preferências, críticas e sugestões dos consumidores, no que diz respeito às mercadorias já disponibilizadas, até aquelas que poderão vir a ser criadas.

Aqui entra em cena a indústria do marketing. Seu trabalho consiste em abrir diferentes canais de comunicação com os consumidores ou usuários e, partindo das opiniões coletadas, criar campanhas publicitárias que facilitem a identificação do consumidor com a mercadoria em questão. Temos aqui um trabalho minucioso e estratégico. Tanto que, para Lazaratto (2004), o setor de marketing é hoje fundamental para a permanência das empresas e/ou dos profissionais no mercado. Ele é responsável pela "criação de mundos" idealizados, a partir dos quais as mercadorias entram em circulação e conseguem atrair a atenção do consumidor, facilitando a sua identificação com o produto e com a marca. Assim, já não basta simplesmente colocar uma nova mercadoria em circulação. Antes, é preciso empreender todo um trabalho imaterial de pesquisa. A partir desses dados, são elaboradas as estratégias publicitárias que procuram tornar as mercadorias mais facilmente vendáveis. A área de marketing, conforme vimos com Lazaratto (2004), ocupa-se de "criar mundos" subjetivos, que serão veiculados às 
mercadorias, favorecendo assim sua venda. Dessa maneira, o consumidor identifica-se primeiramente com esses mundos, para que, aderindo a eles como um ideal a ser conquistado, absorva também as mercadorias. Os "mundos" que as empresas criam devem ser produzidos a partir do horizonte ideal dos trabalhadores e dos consumidores.

Lazzarato (2004, p. 230) diz ainda que atualmente vivemos uma verdadeira "guerra estética" entre os mundos criados pela indústria domarketing. Em tais guerras, já não são os produtos que se destacam, mas as formas de vida a eles veiculadas. Essa modalidade de trabalho imaterial tem por objetivo investigar e criar necessidades de consumo e, para tanto, dedica-se a uma outra tarefa básica: conhecer, do ponto de vista da subjetividade, quem é o consumidor, quais são as suas opiniões e os seus desejos. Os diferentes instrumentos de pesquisa elaborados com o objetivo de conhecer o humano e, mais especificamente, de engendrar nele a necessidade e/ou o desejo por uma determinada mercadoria, localizam-se precisamente aqui.

Uma terceira vertente foi incluída por estes autores na caracterização do trabalho imaterial. Ela diz respeito a uma extensa gama de serviços prestados por uns, que são os trabalhadores, e utilizados por outros, que são os consumidores. O predominante neste contexto é a relação afetiva estabelecida entre as empresas, os profissionais e os usuários. Assim, o trabalho imaterial é também trabalho afetivo, e a área de saúde, da qual a Psicologia também faz parte, oferece um conjunto de exemplos visíveis, como podemos constatar nas palavras dos autores:

Serviços de saúde, por exemplo, baseiam-se essencialmente em cuidados e em trabalho afetivo, e a indústria do entretenimento está, da mesma forma, centrada na criação e manipulação do afeto. Esse trabalho é imaterial, mesmo quando físico e afetivo, no sentido de que seus produtos são intangíveis,um sentido de conforto, bem-estar, satisfação, excitação ou paixão (HARDT; NEGRI, 2001, p. 313).

Em face dessa breve caracterização, pode-se notar que o trabalho imaterial é algo que está presente em todas as profissões, desde aquelas que exigem maior habilidade para a criação, produção de conhecimento e contatos sociais até aquelas que demandam majoritariamente a força física dirigida para atividades repetitivas e rotineiras. Há entre esses dois extremos uma diferença proporcional, visto que atualmente qualquer tipo de atividade profissional exigirá um trânsito entre o trabalho material e o imaterial.

Uma vez que temos claro quais são os diferentes tipos de trabalho que podem ser denominados como imateriais, passamos a refletir sobre as implicações do crescimento desta modalidade profissional na sociedade contemporânea. Para isso, vale ressaltar que a noção de trabalho imaterial, tal como utilizada por esses autores, envolve um meio de produção que confere especial destaque à subjetividade, a qual está muito 
mais operacionalizada no cotidiano laboral, sendo por vezes tratada como um de seus produtos.

Aqui partimos de uma concepção de subjetividade que, segundo Feliz Guattari, é "essencialmente fabricada e modelada no registro do social" (1996, p. 31). Essa produção, de acordo com os estudos da Psicologia Social, envolve um movimento vivo, pelo qual diferentes componentes subjetivos são constantemente postos em circulação na esfera social e, uma vez acolhidos, participam da construção dos modos de viver que são compartilhados por uma coletividade.

É importante considerar que a própria automatização do trabalho, com a introdução de máquinas comandadas por computadores, operou, ao longo das últimas décadas, uma transformação significativa nos modos de subjetivação dos trabalhadores, bem como uma redução dos postos de trabalho ligados à produção material. Assim, proporcionalmente, o trabalho imaterial torna-se mais significativo e amplamente disseminado, ao mesmo tempo em que declinam as atividades braçais. Isso porque a automatização solicita permanentemente a contratação de profissionais ultra-capacitados, detentores de ampla gama de conhecimentos, capazes de conectar-se a sistemas complexos de informações e gerenciá-los. E tais habilidades ajudam a circunscrever o próprio trabalho imaterial.

\section{Do trabalho material ao trabalho imaterial}

Se, como dito anteriormente, novos modos de subjetivação emergem no exercício do trabalho imaterial, cabe analisar, ainda que brevemente, quais as diferenças que existem entre esses dois tipos de produção. No sentido mais clássico, o trabalho material envolvia, e envolve até nossos dias, relações de poder que são centradas na promoção da disciplina sobre os corpos, cujo objetivo está em torná-los, como considerou Michel Foucault, "corpos dóceis" (1998, p. 117). Trata-se de relações que demandam a imitação de atos encadeados, como a cópia de um modelo ou de um procedimento, exigindo-se, para isso, o esforço físico repetitivo. Nesse contexto laboral, praticamente tudo já é conhecido de antemão: o plano de trabalho, o modelo a ser seguido, as estratégias para facilitar a adaptação do indivíduo às tarefas rígidas, aos equipamentos, às regras disciplinares e ao respeito às hierarquias.

No trabalho material, o trabalhador avaliado positivamente é aquele que tem condição de colocar à disposição da fábrica um corpo saudável e forte, capaz de utilizar os seus músculos e sua coordenação motora para realizar, de maneira rápida e eficaz, uma dada atividade, que foi minuciosamente prescrita. Todo o esforço exigido está concentrado na repetição de movimentos encadeados e na disciplina dos indivíduos. 
Como podemos compreender o modo de subjetivação dominante nesse cenário? Temos aqui um indivíduo largamente submetido a uma série de regras padronizadas e elaboradas por um nível hierárquico superior, que impõe condutas e procedimentos a serem reproduzidos num espaço de tempo determinado, o que garante à empresa o índice de produção pretendido.

Em certa medida, cada ação individual é facilmente mensurável e amplamente controlada. Assim o trabalhador disciplinado pode ser concebido como uma parte da máquina e está submetido à cobrança de metas quantitativas de produção.

Gorz entende que esses trabalhadores "só se tornam operacionais depois de serem despojados dos saberes, das habilidades e dos hábitos desenvolvidos pela cultura do cotidiano, e submetidos a uma divisão parcelada do trabalho" (2005, p. 19). Esse despojamento facilitou a construção de corpos dóceis e obedientes.

Um outro ponto a ser considerado é que esse modo de subjetivação disciplinar priorizava a posse de uma identidade a partir da qual era possível fixar cada indivíduo em uma instituição, em um setor de trabalho e em um papel social bem definido. Em larga medida, isso facilitava a sua localização na estrutura institucional. Nesse sentido, Negri e Hardt comentam:

\begin{abstract}
As subjetividades produzidas nas instituições modernas eram como as peças de máquina padronizadas nas fábricas: o detento, a mãe, o operário, o estudante e assim por diante. Cada parte desempenhava um papel específico na máquina montada, mas era padronizada, produzida em massa, e portanto substituível por qualquer parte do seu tipo (HARDT; NEGRI, 2001, p.353).
\end{abstract}

Cabe dizer que, conforme passa o tempo em que o trabalhador permanece ligado a certa ocupação, o seu corpo já não responde da mesma maneira às exigências que Ihe são impostas. Assim, em havendo uma queda de produção, ele pode ser facilmente substituído por um outro trabalhador, cuja energia física ainda esteja inexplorda. Encontra-se aí a importância dos estudos de Karl Marx sobre o exército de reserva de mãode-obra gerada por essa orgnização econômica que, em muuito, contribuiu para aumentar o contingente de indivíduos que são recorrentemente excluídos do mercado de trabalho.

Já no trabalho imaterial, cujo foco está na produção de conhecimento, de imagens e de afetos, uma outra configuração da subjetividade ganha relevância, passando a ser exigida e operacionalizada no cotidiano. Essa nova configuração produtiva busca extrair da vida habilidades que vão além da força física e envolvem dimensões subjetivas que se tornam indispensáveis para garantir a preferência dos clientes e a permanência das empresas no mercado. Assim, segundo Pelbart (2003), as novas 
formas de poder que caracterizam o trabalho imaterial, tomam de assalto o pensamento, a imaginação, a criatividade, a potência (para estabelecer conexões com pessoas e equipamentos), a sensibilidade, a sociabilidade e a afetividade.

Como são solicitadas e obtidas essas exigências ligadas à subjetividade? Boa parte delas depende de uma formação técnica que pode ser encontrada em cursos universitários e de aperfeiçoamento profissional. Entretanto, Gorz (2005) destaca que algumas formas de saber "não são formalizáveis" e, dessa maneira, não são acessíveis por treinamento técnico. Elas englobam, diz o autor,

O saber da experiência, o discernimento, a capacidade de coordenação, de auto-organização e de comunicação. Em outras palavras, formas de um saber vivo, adquirido no trânsito cotidiano, que pertence à cultura cotidiana. O modo como os empregados incorporam esse saber não pode ser nem predeterminado nem ditado (GORZ, 2005, p.9).

Quando analisamos a realidade brasileira, pode-se notar que existe uma "hibridização" (NEGRI, 2003, p. 102) entre os modos de produção material e imaterial. O "saber vivo" presente nos processos de concepção, criação e inovação, não elimina as atividades repetitivas e as rotinas que organizam o trabalho das fábricas, por exemplo. Entretanto, ele serve para sofisticar a maneira como essas atividades são realizadas, aproximando cada vez mais os produtores dos consumidores.

Além disso, a marca diferencial deste tempo histórico está no fato de que os resultados do trabalho material só encontram lugar no mercado quando acrescidos da dimensão imaterial, visto que a mera disponibilização da mercadoria já não é mais suficiente para garantir a sua venda. Toda a dimensão imaterial existe para que os consumidores sejam atraídos não somente pelos produtos propriamente ditos, mas também pelas maneiras de viver e pelas formas de se relacionar. Tais produtos, por estarem associados aos estilos de vida que são moldados e disseminados pela publicidade, possuem grande apelo subjetivo.

\section{Produção de subjetividade e trabalho imaterial}

Nas relações de produção que se configuram na contemporaneidade, a subjetividade encontra-se presente nas duas extremidades do processo: do lado do trabalhador, que comparece com o seu corpo, seu psiquismo, sua linguagem, sua comunicação, enfim, com a sua vida inventiva que é acionada par a produção; mas também do lado do consumidor, que adere aos apelos das campanhas publicitárias, consumindo formas de existência formatadas, com as quais ele se identifica e passa a desejar para si. Ao consumir, ele é convidado a expressar suas opiniões, fornecendo às 
empresas uma série de informações que servem para redefinir as estratégias de produção, de distribuição e de venda adotadas.

E como isso se dá? No que diz respeito ao trabalhador, podemos dizer que são requisitadas dele aquelas habilidades extraídas da vida cotidiana que exigem a sua potência de criação, conforme analisado anteriormente. A utilização dessa dimensão da existência, esse "poder de criação" (NEGRI; HARDT, 2001, p. 410), é altamente estimulado e torna-se hoje uma das principais fintes de produção de riqueza capaz de manter o mercado sempre dinâmico, com a substituição constante de mercadorias e de serviços, num movimento que é aquecido pelas novidades e lançamentos. O capitalismo fomenta a potência de invenção de sues trabalhadores, estimulando a experimentação do novo e do desconhecido, seja na busca de soluções para os problemas, seja na própria invenção de novos problemas que, por sua vez, se reverterão em novidades para movimentar o mercado.

Ao reconhecer a subjetividade como uma fonte de produção de riqueza, as empresas estimulam o exercício da invenção no cotidiano do trabalho com o objetivo de transformar seus resultados em novas mercadorias, que serão então produzidas em série e posteriormente consumidas pela população, que engloba também os próprios inventores.

Vejamos um exemplo: os estilistas e pesquisadores das empresas que trabalham no ramo da moda estão permanentemente atentos para detectar as invenções que se efetuam nas ruas dos grandes centros urbanos. Boa parte das tendências difundidas por esses profissionais em grandes eventos de moda é produzida no cotidiano de pessoas anônimas que experimentam novas formas de se vestir. Ao detectar as invenções que aí se fazem presentes, o trabalho desses profissionais consiste em copiá-las, formatá-las num certo padrão, fabricá-las em série e, posteriormente, revendê-las como "novidades".

Em síntese, podemos dizer que se operou, nas últimas décadas, uma espécie de sequestro da força inventiva presente no cotidiano. Paralelo a isso, é empreendida a criação de mundos subjetivos que são agregados às mercadorias, intensificando-se a sua venda. Em qualquer um desses momentos, é a própria vida subjetiva que se encontra em evidência, sendo tomada como uma espécie de matéria-prima que serve para promover a circulação de dinheiro.

Mas é preciso dar um passo adiante e considerar que, atualmente, o processo aqui descrito caracteriza-se também por uma intervenção no desejo coletivo. Com isso, tanto a produção quanto o consumo não acontecem pela simples obediência, mas pelo desejo de, uma vez consumindo, experimentar a sensação de pertencer àqueles mundos glamurosos, que foram criados pelo marketing. $E$ isso se deve, em parte, à maneira como esses mundos são elaborados, atravessados pela idealização ou pela fantasia de que existem seres completos, plenamente 
satisfeitos, sem conflitos ou dificuldades e, principalmente, pela disseminação da idéia de que esses mundos são acessíveis apenas a algumas pessoas que são financeiramente selecionadas.

Jurandir Freire Costa destaca que os atores escolhidos para atuar nas campanhas publicitárias são geralmente avaliados pela população como belos e aparentam estar satisfeitos o tempo todo. Daí o fato deles serem chamados de "celebridades" (COSTA, 2004, p.170). Por intermédio dessas imagens impecáveis de satisfação e prazer, vende-se a promessa ilusória de que consumir tais mercadorias aproximaria o sujeito da possibilidade de pertencer a esses mundos e de também alcançar uma ideal, uma vida isenta de conflitos. Pode-se pertencer que toda uma nova política de inclusão e exclusão sociais toma forma. É como se a possibilidade de consumir funcionasse como uma oportunidade para sair do anonimato.

\section{Trabalho I material e Resistência}

Quando analisamos estas relações de produção que, na contemporaneidade, procuram explorar a vida em sua dimensão mais criadora, corremos o risco de achar que está última encontra-se totalmente subjugada e controlada por um processo sistemático de expropriação da vitalidade e da criação coletivas.

Entretanto, esta é uma conclusão demasiadamente rápida. Com a Psicologia Social, aprendemos que qualquer dimensão da vida humana encontra-se em movimento de construção e de desconstrução. Isso se evidencia também nos trabalhadores envolvidos com a esfera das atividades imateriais. Existe aí uma dinâmica singularizada que apresenta grande potencial para operar mudanças no cenário do trabalho. Esta dinâmica pode ser descrita com uma troca intensa dos mais diferentes tipos de conhecimentos. Por meio dessas trocas, os trabalhadores deixam de ser meros executores de funções rígidas, agregando gradativamente conhecimentos e competências que são produzidos em áreas adjacentes à sua. Tal movimento conta ainda com o auxílio de uma rede mundial de computadores e cria condições para que o trabalhador redefina sua carreira profissional com base no conhecimento adquirido nesse complexo processo de aprendizagem.

Assim, a expansão do trabalho imaterial torna-o ao mesmo tempo social, comunicativo e afetivo, podendo aumentar a potência de ação e de expansão dos agentes que o executam. Nessa direção, Negri e Hardt (2001) assinalam que um outro ponto fundamental para a compreensão do trabalho imaterial e suas repercussões para a vida do trabalhador é 
que ele envolve, necessariamente, a noção de cooperação, sendo esse um requisito indispensável para sua efetuação. Para esses autores:

a cooperação é totalmente inerente ao trabalho. O trabalho imaterial envolve de imediato a interação a cooperação sociais. Em outras palavras, o aspecto cooperativo do trabalho imaterial não é imposto e organizado de fora, como ocorria em formas anteriores de trabalho, mas a cooperação é totalmente imanente à própria atividade laboral (HARDT; NEGRI, 2001, p. 315).

Por cooperação estes autores compreendem a existência de uma multiplicidade de sujeitos envolvidos na execução de qualquer atividade, cada um deles participando a sua maneira. Essa participação, por sua vez, conta com o exercício de habilidades variadas que são utilizadas de maneiras e em graus distintos. Nota-se aqui que a capacidade inventiva não é restrita a homens que têm grandes idéias, mas é o resultado da cooperação entre uma infinidade de agentes. Em geral, essas idéias são anônimas. Por meio das inúmeras conexões entre os trabalhadores, a invenção é fomentada. Assim, é da cooperação e dos processos de aprendizagem, que se desdobram a partir dela, que o responsável por executar um trabalho, seja ele material ou imaterial, pode experimentar uma relação diferenciada com suas atividades cotidianas e com os demais indivíduos que dela participam.

O trabalhador, neste caso, extrai diretamente da sua trajetória de vida e do conhecimento adquirido nas relações com os outros, formas diferenciadas de inserção no mundo do trabalho. É em razão disso que, nas relações de produção imaterial, o produto (em forma de conhecimento, relações sociais ou afetos) não depende exclusivamente dos meios de produção material. Ao contrário, para Gorz "é ao se difundir como bem acessível a todos que ela engendra conhecimentos suplementares" (2205, p. 53). Assim, a cooperação, a troca, a circulação de saberes tornam-se condições essenciais para que o trabalho seja executado de maneira eficiente.

A essa altura já podemos questionar novamente: Quais modos de subjetivação são engendrados pela organização do trabalho imaterial? Negri e Hardt dizem que, nesse cenário, "o sistema disciplinar torna-se totalmente obsoleto, e precisa ser deixado para trás" (2001, p. 297) em favor das novas demandas mas também dos novos desejos que são construídos nas relações de produção, seja na esfera do trabalhador seja naquela que envolve o consumidor. Os autores denominam esse novo modo de existir como uma "subjetividade híbrida' (2001, p. 353) que é mais mutante, flexível e, pode-se dizer, mais fragmentada. Essa configuração subjetiva cria condições para que o trabalhador assuma diferentes papéis sociais e realize atividades variadas transitando, ao mesmo tempo, pelos mais diversificados contextos a fim de executar funções mais complexas que são voltadas para a comunicação, a criação e 
os contatos sociais. Com isso, o trabalhador já não pode ser reduzido mais a uma identidade conhecida e cristalizada em um único papel social. No trabalho imaterial, a vida inventiva ganha uma importância diferencial à medida que é reconhecida como uma força soberana e constitutiva do trabalho e do própria sujeito que o executa. O que acontece é que ela encontra-se às voltas, o tempo todo, com diferentes aparelhos de captura. Entretanto, ela nunca está totalmente capturada. Segundo Pelbart (2003), a existência tornou-se, também ela, um capital, uma fonte de riqueza, em especial para o trabalhador. As produções imateriais que são efetuadas na contemporaneidade afirmam-se graças à vitalidade da força inventiva presenta no cotidiano e, de maneira mais específica, nas relações profissionais. Trata-se de uma vitalidade social que comporta a potência de afetar e de ser afetado, o desejo de aumentar conexões e de, assim, produzir novas possibilidades de resistência.

Nessa perspectiva de análise, é a vida que nutre a produção de capital. E é precisamente sobre ela que a organização econômica capitalista tenta, o tempo todo, operar uma "função parasitária" (NEGRI, 2003, p. 96) de exploração. Assim, aquilo que foi denominado anteriormente como força inventiva não emana em primeira instância dos poderes instituídos. Ao contrário, é a força-invenção que nutre esta forma de poder econômico. E ela é atualizada pela potência psíquica e política que habilita em todos e em cada um dos trabalhadores.

\section{Considerações Finais}

Tendo percorrido as transformações que se vêm efetuando nas relações de trabalho, pode-se dizer que no tempo histórico atual, vários regimes de produção coexistem e estão amplamente ativados: a disciplinarização dos corpos no contexto laboral continua presente (especialmente em nosso país), dividindo espaço com a incitação do desejo, a "vampirização" da força-invenção e as intervenções da publicidade que geram diferentes efeitos junto à população de trabalhadores e consumidores. Desta maneira, uma análise que envolva a mera oposição entre indivíduo e capital já não dá mais conta de lidar com a complexidade que ora vivemos nesta esfera da existência.

Existem diferentes movimentos de reversibilidade entre um poder que pretende controlar a vida e uma potente que é capaz de produzir novas formas de resistência à medida que, também ela, é uma fonte de conhecimento e de valor. Essa reversibilidade irredutível que se faz presente em toda e qualquer relação de poder exige outros instrumentos de análise, mais sofisticados do que a simples oposição entre esses dois pólos. 
É precisamente deste novo trabalhar, que age segundo uma dinâmica complexa e ainda pouco conhecida, que novas demandas de pesquisa tomam corpo. Isso porque, possivelmente, uma apropriação da existência em sua dimensão mais viva, afetiva e autônoma está presente nessa tendência psicossocial contemporânea que está em plena construção. $O$ desfio que nos é colocado numa investigação dessa natureza consiste precisamente em, implicados e mergulhados nesse novo cenário, caracterizar estas novas dimensões subjetivas que ganham força, em especial aquelas voltadas para a afetividade, e que são exigidas do trabalhador em sua atividade imaterial.

A ênfase na subjetividade e na sua potência de criação, entretanto, pode enredar os trabalhadores em quadros psicopatológicos que se tornam cada vez mais comuns, como é o caso do stress, da depressão e do pânico emergentes a partir das relações de trabalho. A situação fica ainda mais complexa quando algumas dimensões da existência, outrora confinadas na esfera da vida privada, passam a ser mais tematizadas e exercitadas no cotidiano das relações profissionais fazendo desaparecer os limites entre a vida privada e o trabalho.

Ao mesmo tempo, cresce a cada dia a quantidade de trabalhadores que tem condições de trabalhar em suas próprias casas ou daqueles que, independentemente de sua vontade, acabam levando para o contexto da vida privada os problemas que dizem respeito à empresa como, por exemplo, a preocupação com as metas que devem ser cumpridas, os problemas e as soluções que para eles devem ser elaboradas bem como as situações de competitividade e conflitos enfrentadas.

Mas, sobre essa aproximação e sobre as repercussões subjetivas por ela desencadeadas ainda temos muito a investigar. De qualquer maneira, Gorz destaca:

A experimentação de outros modos de vida e de outras relações sociais nos interstícios de uma sociedade que se desagrega, serve para atacar e deslegitimar o controle que o capital exerce sobre os espíritos e os corpos. Os constrangimentos e os valores da sociedade capitalista deixam de ser percebidos como naturais, liberando os poderes da imaginação e do desejo (GORZ, 2005, p. 71).

Portanto, é acreditando nessa potência de variação e de expansão colocadas em curso no exercício do trabalho imaterial que as relações profissionais podem ser desnaturalizadas e abordadas como um campo vivo onde são ensaiadas as mais diferentes transformações da subjetividade.

\section{Referências Bibliográficas}


COSTA, J. F. O Vestígio e a aura: corpo e consumismo na moral do espetáculo. Rio de Janeiro: Garamond, 2004.

FOUCAULT, M. Vigiar e punir: história da violência nas prisões. Petrópolis: Vozes, 1998.

GORZ, A. O I material: conhecimento, valor e capital. São Paulo: Annablume, 2005.

GUATTARI, F.; ROLNIK, S. Micropolítica: cartografias do desejo. Petrópolis: Vozes, 1996.

HARDT, M.; NEGRI, A. I mpério. Rio de Janeiro: record, 2001.

LAZZARATO, M.; NEGRI, A. Trabalho I material: formas de vida e produção de subjetividade. Rio de Janeiro: DP\&A, 2001.

LAZZARATO, M. Créer des Mondes: capilalismo contemporain et guerres "esthétiques". Multitudes, Montigny le Bretonneux, n. 15, p. 230-237, 2004.

NEGRI, A. Cinco lições sobre império. Rio de Janeiro: DP\&A, 2003.

PELBART, P. P. Vida capital: ensaios sobre biopolítica. São Paulo: Iluminuras, 2003.

\section{Endereço para correspondência}

Sonia Regina Vargas Mansano

Universidade Estadual de Londrina, Departamento de Psicologia Social e Institucional,

Rodovia Celso Garcia Cid, PR 445 Km 380, Campus Universitário, Londrina, Paraná, Brasil

Endereço eletrônico: mansano@uel.br

Recebido em: 12/01/2009

Aceito para publicação em: 29/06/2009

Editor responsável: Eleonôra Torres Prestrelo

\section{Notas}

* Doutora em Psicologia Clínica pela Pontifícia Universidade Católica de São Paulo - PUCSP, São Paulo, SP, Brasil. 